UDC: 821.134.2.09 Wenceslao A.

DOI: https://doi.org/10.18485/beoiber.2017.1.5

\author{
Snežana Jovanović ${ }^{1}$ \\ Doctora por la Universidad Complutense de Madrid \\ España
}

\title{
MUJERES, VESTIDOS Y MODAS EN EL UNIVERSO DE WENCESLAO AYGUALS DE IZCO
}

\begin{abstract}
Resumen
Este trabajo es un intento de aproximación a la obra de Ayguals de lzco y a la sociedad decimonónica representada en su narrativa a través del análisis de las costumbres y modas que imperaban en España, sobre todo en Madrid de los mediados del siglo XIX. Nuestras observaciones se centran en su famosa trilogía (María o la hija de un jornalero, Marquesa de Bellaflor o el niño de la Inclusa, Palacio de los crímenes o El pueblo y sus opresores) y en otras tres novelas: Pobres y ricos o la bruja de Madrid, Los pobres de Madrid y La Justicia divina o El hijo del deshonor.
\end{abstract}

Palabras clave: Ayguals de Izco, moda, costumbres, novela por entregas, sociedad española.

\section{WOMEN, DRESSES AND FASHION IN WENCESLAO AYGUALS DE IZCO'S UNIVERSE}

\begin{abstract}
This essay is an attempt of approach to the work of Ayguals de Izco and nineteenth-century society represented in his narrative through the analysis of prevailing customs and fashion in mid-nineteenthcentury Spain. Our analysis is based on his famous trilogy (María o la hija de un jornalero, Marquesa de Bellaflor o el niño de la Inclusa, Palacio de los crímenes o El pueblo y sus opresores) and three other novels: Pobres y ricos o la bruja de Madrid, Los pobres de Madrid and La Justicia divina o El hijo del deshonor.

Key words: Ayguals de Izco, fashion, customs, serial novel, Spanish society.
\end{abstract}

Ayguals de Izco, el gran cronista de su tiempo, pintor de las costumbres y de la realidad española, no pudo menos que dejar constancia de las modas de la época, ya que la moda, igual que las costumbres, es un elemento importante de la cultura de un pueblo, de su sociedad e idiosincrasia. Su preocupación por presentar de manera objetiva todo lo

\footnotetext{
1 jovanovic.nena@gmail.com
} 
que le rodea se expresa en la pintura de diversos aspectos de la vida cotidiana que incluyen desde las costumbres que define como "sociales", hasta los hábitos y comportamientos en la vida privada. Sus dotes de observador minucioso destacan sobre todo en los retratos de los numerosos personajes que desarrolla en sus voluminosas novelas. Estas descripciones cumplen un variado haz de funciones: en primer lugar sirven para la pintura moral y física de los personajes y para distinguir la clase social a la que pertenecen, y luego para plasmar y mostrar los formalismos convencionales de la sociedad y el sentido de disfraz y falsedad en las relaciones humanas. Es bien conocida la vena práctica y emprendedora del escritor vinarocense al que muchos investigadores consideran el precursor del marketing moderno. Por eso no sorprende que muy pronto se diera cuenta del hecho de que las mujeres paulatinamente se estaban convirtiendo en una parte significativa del público lector de las novelas. Valiéndose de su casa editorial y del buen conocimiento de los gustos del público, se empeña en ofrecerles contenidos que responden a sus intereses. Es consciente de que los detalles sobre la moda son uno de los elementos que atrae al público lector femenino, de ahí que predominen las descripciones de la moda femenina. A menudo se afirma que los autores de la afiliación de Ayguals nunca se fijan en la manera de vestir de los hombres y "solo se interesan por la mujer, sus ropas, joyas, casas, coches" (Carmona González 1990: 185), pero en el caso de nuestro escritor esta afirmación es poco aplicable, dado que proporciona muchos detalles de los trajes masculinos, de lo que visten no solo en la sociedad, sino también en la privacidad de sus hogares, complementos como guantes o pañuelos, pinceladas sobre la moda de peinar, modelar bigotes y barbas. Sin embargo, hay que reconocer que la profusión de detalles es más característica en la descripción de los atuendos femeninos. Un retrato del escritor que hemos conseguido rastrear en el periódico madrileño $L a$ Voz, publicado el 19 de noviembre del 1928, cincuenta años después de su muerte, podría echar algo de luz sobre el origen de su interés por la moda, numerosas referencias a la indumentaria y la prolijidad de detalles en las descripciones de los atuendos de sus personajes. El autor del artículo, Juan López Núñez enfatiza tanto algunos rasgos de su carácter, como los de su aspecto físico:

Ayguals de Izco gustaba de vestir muy bien. Con una pose a la francesa, imitaba en la indumentaria a sus hermanos los folletinistas de la vecina República. Así con una apostura señorial a lo Ponson du Terrail, se complacía en retratarse en una actitud aristocrática, pero desdeñosa para todos los principios admitidos hasta entonces. Parecía que deseaba que todos lo creyesen dueño y poseedor de todos los secretos del mundo que fustigaba.

\section{¿Qué es lo que llevan las mujeres?}

Sus atuendos dependen de la clase social a la que pertenecen, igual que de la ocasión para la que se visten. En la prensa de la época, revistas de moda o manuales de 
protocolo se publicaban las reglas de cómo ir bien vestido. La prolijidad de detalles con la que el escritor describe la vestimenta femenina hace pensar a varios investigadores que Ayguals los consultaba buscando la inspiración para los atavíos de sus personajes femeninos. Para hacer presencia en la sociedad en algún evento diurno, los vestidos suelen ser largos y vaporosos, sobre todo en verano. En 1834 en la carretela abierta de la marquesa de Turbias-Aguas, María acapara la atención de todos los presentes en el paseo del Prado con su sencillo, pero elegante vestido. En esta descripción aparecen algunas prendas típicas del vestuario de la época:

[...] la falda de su precioso vestido era de precioso tafetán con listas de color de rosa sobre fondo castaño; spencer de raso negro con jockeys en las mangas de transparente gasa; chal de cachemira de Persia que caía en gracioso y undulante abandono, como queriendo descubrir la angosta y flexible cintura de aquella candorosa joven, formaban el traje de María. (María t. I: 195)

El spencer es una chaquetilla corta, en España más conocida como juboncito, que se usó como prenda de abrigo cuando se impuso la moda de los vaporosos y finos vestidos camisa. El de María, la protagonista de la trilogía de Ayguals, lleva un adorno adicional - jockeys, especie de hombrera o sobremanga semejante a la del traje de jinete profesional. El chal de cachemira es un complemento lujoso e imprescindible en la moda burguesa de la época. Suelen ser de las India o de Persia. Otro detalle que señala Ayguals es la "angosta y flexible cintura", el ideal femenino de la época. Por eso la forma de la falda, mangas anchas y otros detalles de los vestidos que se llevan, acentúan esta parte del cuerpo. En casi todas las descripciones de los personajes femeninos se hace referencia a la cintura, sobre todo si son chicas jóvenes. Igualmente, en la pintura de las mujeres ya de edad avanzada, si son personajes negativos, la ausencia de la misma en su cuerpo le sirve para ridiculizarlas. Parece que la cintura y estatura delgada están bien vistos en los cuerpos masculinos también: "Los jóvenes del día, lo sacrifican ustedes todo al buen parecer. Ya se ve, como es moda ser delgados, y tener buena cintura como las mismas señoritas a quienes tratan de agradar, se abstienen de comer hasta el extremo de perder el color y quedarse en los huesos" (Los pobres de Madrid: 72). Con el mismo fin de destacar la cintura se utilizan los miriñaques que, aunque muy poco prácticos, han marcado todo el siglo XIX. Por ese motivo solo formaban parte de los vestuarios de las mujeres de las clases altas que llevaban una vida ociosa. A este invento Ayguals se refiere como "ahuecador", ya que servía para dar volumen o ahuecar la falda. La siguiente cita es una de las pocas en la que se alude a esta prenda interior o, mejor dicho, estructura:

Un abrigo de terciopelo negro contrastaba con la blancura del camisolín y de las mangas bordadas, cubriendo pecho y espaldas de un modo violento producido por cierto promontorio natural que se elevaba por un lado más que por otro, desnivelando de una manera notable las proporciones de hombros y espaldas. La 
falda de su vestido de raso azul abultada por su correspondiente ahuecador, estaba adornada con tres volantes. Este volumen recibía el nuevo aumento de un enorme manguito, donde la heroína tenia metidas las manos ya resguardadas por los indispensables guantes pajizos. (Los pobres de Madrid: 387-388)

No es casual que le ponga esta prenda que no se ha ganado su simpatía a la tía Manuela, uno de los personajes negativos que presenta los rasgos de las antiguas celestinas. En más de una ocasión expresa odio hacia las mujeres viejas, sobre todo si son malvadas como esta. Además de ser inmoral, vieja y jorobada, es culpable de ir vestida a la última moda procedente de París, lo que le convierte en el blanco de burla del escritor. Es contraposición al ideal femenino y reúne todas las características indeseables en una mujer, lo que se refleja en su atuendo: recargado, excesivo, superabundante, todos sinónimos de mal gusto en opinión de nuestro escritor

Ayguals demuestra muy buen conocimiento tanto de la moda femenina, como de las telas y complementos. En el corto ejemplo anteriormente citado, aparecen hasta tres telas diferentes: tafetán, raso, cachemira. Siempre se fija en la tela como si la belleza de los tejidos fuera más importante que el diseño. La tela que más aparece es raso, seguido de seda. Para ir a la ópera María y su hermana Rosa eligen vestidos de raso: la primera, uno de color morado oscuro con el cuello de encaje y Rosa un vestido de color lila con tres volantes (Marquesa de Bellaflor t. I: 35). El autor señala su elegancia y buen estilo ya que se "separan de esa costumbre vulgar y de mal gusto" de ir "ataviadas idénticamente" siendo hermanas. El muaré (moaré) o moiré como lo llama Ayguals, es uno de los tejidos favoritos de los nobles y de la alta burguesía. Es un tejido refinado y muy costoso, fabricado con seda y de compleja elaboración. Por su precio elevado ni los más poderosos podían llevarlo todos los días y lo reservaban solo para las ocasiones especiales, bailes y fiestas, situaciones cuando había que demostrar el poderío y cierta posición en la sociedad. El día de su boda, la reina Isabel Il brilla en un vestido de muaré blanco "con tres órdenes de blonda argentina" (Marquesa de Bellaflor t. II: 291). Esta tela también se encuentra en algunos complementos de moda: María para la visita del marqués de Bellaflor “miró si tenía bien colocado el medallón que llevaba pendiente de una cinta negra azulada de moiré" (María t. II: 18).

Por otro lado, los vestidos de los pobres suelen ser de las telas gruesas, resistentes, más baratas y lavables como son mahón, estameña y percal, dado que deben cumplir por encima de todo su función principal, la de abrigar y proteger. El predominio de los colores oscuros, sobre todo negro y marrón, podría explicarse por motivos igual de prácticos: la suciedad y las manchas se notaban menos. El pintor Lucas sueña con ver a su novia, la ramilletera Carmen, en uno de esos ricos vestidos de seda que lucen las señoritas de las familias adineradas, pero la ramilletera, mucho más realista que su novio, responde: "Mejor es percal, que se lava cuando se ensucia" (Los pobres de Madrid: 84). A diferencia de las chicas de familias ricas, lo más habitual para las jóvenes y mujeres pobres era tener un traje que llevaban todos los días y como mucho alguna prenda para las festividades. Todo lo que posee María, la hija un jornalero, son "dos vestidos de percal, 
uno muy oscuro y otro de color de mahón con listas moradas; y una mantilla bastante deteriorada completaban las galas de aquella virtuosa caricatura, que a pesar de la escasez presentábase siempre bien compuesta y limpia" (María t. I: 136).

El característico dualismo moral de Ayguals de Izco también se refleja en los vestidos de los personajes de procedencia humilde: a los buenos, virtuosos y morales, los retrata con vestidos pobres, pero siempre impecablemente limpios; en los malos al contrario insiste en la falta de aseo. Con el mismo fin, a menudo señala la relación entre el espacio en el que viven los pobres y su vestuario como en el caso de María en cuya casa "notábase el mayor aseo, tanto en los pocos y ordinarios muebles que había en ella, como en los remendados vestidos" (María t. l: 28). Los más menesterosos, entre los que encontramos la gente decente sin trabajo, pero también prostitutas y otros tipos que se mueven en los márgenes de la sociedad, carecen tanto de medios, como de ganas para pensar en lo que llevan puesto. La ropa es para ellos una necesidad y cumple solo una función práctica; sus andrajos, ropa rota y desaliñada tiene que protegerles del frío del invierno y los calores de verano. Las mujeres del figón de la tía Marciana pertenecen a este grupo, la mayoría no lleva medias, algunas ni zapatos, "vestían trajes asquerosos, llenos de roturas, que dejaban ver el atezado cutis de sus descarnados cuerpos" (María t. II: 44).

\section{Vestir a la española y vestir a la francesa}

Vestir a la española ya no está de moda. Los pocos que siguen apegados a los usos de los trajes populares suelen ser los mayores o la gente del pueblo que viviendo en Madrid no ha cambiado sus costumbres antiguas, lo que se evidencia en su manera de vestir. En Ayguals encontramos varias referencias a los trajes de otras zonas de España, sobre todo de Andalucía. La señora Damiana, vestida de macarena, "todavía presumía con su zagalejo corto, mantilla de ancha tira de terciopelo echada a la espalda, peineta terciada y cesto de trenzas" (María t. I: 118)2. Para una fiesta Juanilla también aparece vestida de macarena “con su zagalejo corto, mantilla terciada, castañuelos en los dedos y una guitarra" (Bruja de Madrid t. I: 235). Los jóvenes madrileños, ni siquiera de las clases trabajadoras, ya no lo llevan a diario, lo lucen en los días de fiesta o para ir a los toros. Théophile Gautier en su libro recoge estos cambios, quejándose de los cambios operados en España y de que ya no había verdaderas manolas en las calles de la capital ${ }^{3}$. Ayguals

\footnotetext{
${ }^{2}$ Idéntica descripción encontramos en Mesonero Romanos (1842: 82--83): “[...] parecía la otra moza como de veinte y dos, esbelta y rozagante, con su zagalejo corto mantilla de ancha tira de terciopelo echada a la espalda, peineta terciada y cesto de trenzas en la cabeza".

3 T. Gautier (1985: 96-97): “La manola es un tipo desaparecido, como la griseta de París, como las transtiberinas de Roma; existe aún, pero despojada de su carácter primitivo. Ya no lleva su traje atrevido y pintoresco [...]. He buscado la manola pura sangre por todos los rincones de Madrid: en los toros, en el
} 
lamenta y critica este afán de abandonar lo auténtico y lo único de las españolas para imitar las modas foráneas. Para él, "la verdadera elegancia está en tener el gusto propio" (Justicia divina t. I: 500). La manola de Ayguals a menudo añora una vida lujosa de paseos, teatros, siente desdén por las prendas típicamente españolas, contagiada por las influencias venidas de fuera y sigue ciegamente modas foráneas. Tal es el caso de Toñica la Garbosa que intenta cambiar su apariencia vistiendo elegantes vestidos, pero su origen delata el comportamiento y cierto descaro.

[...] Estaba hechicera cuando iba sencillamente vestida del traje negro y mantilla blanca o viceversa, pero el afán de enaltecerse por la riqueza y forma de vestidos, afán general en las mujeres, y que perjudica a las que están dotadas de cierta donosura y donaire peculiares de las españolas, hacíanla seguir escrupulosamente las modas de París, esto es de los figurines de París [...]. (Justicia divina t. I: 500)

Otro rasgo característico es su propensión a reñir por todo, porque la manola más que un tipo de mujer es un carácter. Ayguals en sus novelas alude a la evolución de la manola en loreta, suele referirse a este tipo como "una de estas que en otros tiempos se llamaban manolas" (Los pobres de Madrid: 86).

En general, los ricos y aristócratas imitan las modas parisinas, los ricos nuevos y los menos adinerados imitan a los nobles en el vestuario. Ayguals en esta imitación distingue diferentes grados que siempre tienen que ver con la salida de tono y falta de mesura. Como todo en la sociedad, las modas tienen sus reglas y los que no las respetan se arriesgan a provocar malos comentarios y quedar en ridículo. Las pobres loretas, por su pobre origen confunden los modelos con figurines, les falta "señorío" e intentan compensarlo con los consejos de los periódicos sobre la moda. Este quiero y no puedo también está criticado por Ayguals, los vestidos ricos no son suficientes, hay que saber cómo y cuándo ponerlos:

Para ellas no había diferencia en las horas del día. Las distinciones de los trajes de negligé, de paseo, de tertulia o de baile les eran de todo punto desconocidas, y creían que para parecer señoras, era preciso mostrarse a todas horas engalanadas de prendas de mucho valor. (Bruja de Madrid t. I: 281)

Una prenda que adquiere una relevante importancia en el siglo XIX es la mantilla. Anteriormente considerada como característica del pueblo, en esta época entra en los vestuarios de las damas de la corte y de los altos estratos sociales en diversos actos sociales, gracias a la influencia de la reina Isabela II. Para Ayguals la mantilla es el símbolo de las clases populares y de lo español, pero también representa un punto de conciliación entre las clases por ser prenda preferida de todas las mujeres, tanto pobres como las ricas.

jardín de las Delicias, en el Nuevo Recreo, en la fiesta de San Antonio, y no he podido hallar ni una completamente castiza".

BEOIBERÍSTICA Vol. I / Número 1 (2017) | 81-92 
La mantilla es obligatoria como pieza para lucimiento en la calle incluso para las mujeres más pobres: Paquita la florera, aunque en situación precaria tiene en su posesión esta prenda tan importante. Es regalo de su vecina y amiga señora Águeda. Para un paseo en carretela con la marquesa de Bellaflor luce su mejor vestido y su mantilla nueva. La corrida de toros o la fiesta de San Isidro son los escenarios predilectos del escritor por su carácter democrático porque es ahí donde es posible ver todas las capas de la sociedad española y donde "la fastidiosa etiqueta estaba prohibida, confundíase el frac con la chaqueta, el chal con la mantilla de manola, no había distinciones de sexo ni edades" (María t. I: 236).

\section{Complementos y peinados}

En los atuendos de las jóvenes de las clases adineradas, claramente, se nota mayor variedad de complementos: sombrillas, sombreros, guantes, abanicos y joyas. De la sombrilla apenas hay menciones, la única que hemos localizado pertenece a la ya mencionada Toñica y le sirve al escritor para ridiculizar los intentos de la loreta de aparentar una gran señora: "la sombrilla, que sin hacer gran sombra, amenaza saltar los ojos de los transeúntes que traten de admirar muy de cerca los encantos de la beldad" (Justicia divina t. I: 500).

Para una dama salir a la calle sin guantes era inapropiado e impensable. Los había de todos los colores, de acuerdo con la ocasión y el color del vestido pero predominaban los colores claros. En las novelas analizadas con más frecuencia son blancos, como los que llevaba la reina María Cristina o pajizos. Los de buena calidad tenían que ser de cabritilla. Era habitual llevar las sortijas y brazaletes encima de ellas. A pesar de ser uno de los elementos obligatorios del atuendo de la época, los guantes femeninos no atraen demasiado la atención de Ayguals. Su función es más destacar las joyas que llevan los personajes o su elegancia que el mismo complemento.

Ayguals presta menos atención al sombrero femenino que al masculino, a lo mejor porque este complemento tenía entre algunas clases la alternativa de la mantilla. Aún así, de sus novelas se puede deducir que para su uso también existían reglas. Aunque se usaban en todos los lugares y todas las ocasiones, el tipo de sombrero y material del que estaba hecho dependían del momento del día, de la situación y de la circunstancia, cuanto más formal, más formal era el sombrero. María para la ópera lleva un sombrero del mismo color que su vestido, "guarnecido de triple punta" con el único adorno de una cinta y una pluma (Marquesa de Bellaflor t. I: 35). En otra escena el mismo personaje vemos con el "sombrerito de paja" como intenta huir con el negro Tomás de la casa de la marquesa Turbias-Aguas (María t. II: 158). A veces los sombreros tenían un velo como el que lleva la tía Manuela, el suyo es de terciopelo azul con «el velo blanco de seda moteado" (Bruja de Madrid t. II. 387). Toñica la Garbosa se olvidó de su mantilla para 
llevar el sombrero a la francesa "que se desprende del moño a guisa del gorra de cuartel en cabeza de quinto, dejando toda la frente en el intemperie" (Justicia divina t. I: 500).

El elegante complemento de abanico al principio tuvo un papel práctico, servía para darse aire y refrescarse. Con el tiempo se acentúa su función decorativa y en el siglo XIX, sobre todo durante la regencia de María Cristina, se convierte en uno de los complementos imprescindibles en el atuendo de las damas. Aunque no es un invento español, "es mueble de grandes recursos para las coquetas españolas" (Bruja de Madrid t. I: 404), Según Ayguals, lord Byron no se quedó inmune ante su belleza, como sus armas cita la mantilla y el abanico que se convierte en "puñal homicida" de la coquetería española (Justicia divina t. I: 71). Al contrario de lo que se podría esperar, el vinarocense no se detiene en la pintura de los detalles de los abanicos; el de la reina describe simplemente como "de valor inmenso". No sabemos casi nada de su aspecto, sobre las telas que se utilizaban o las imágenes pintadas. En sus novelas el abanico suele aparecer en las escenas que describen el comportamiento coqueto de las mujeres. Elisa aprendió este arte de su madre y Ayguals siempre la representa con uno. A veces le sirve para esconder su mirada, otras para fingir rubor o para expresar impaciencia abriéndolo y cerrándolo. De todos los movimientos, el de abrir y cerrar el abanico, es el que con más frecuencia expresa la coquetería para Ayguals.

Entre las joyas Ayguals señala las perlas como joya por excelencia: "Las perlas... ioh! Las buenas perlas son de última moda... es lo más distinguido que se usa en el día... iY qué bien están a las rubias! iQué hermoso contraste forman con su tez de nieve y sus adorados bucles!» (Los pobres de Madrid: 438). El marido, en algunos casos amante, lograba elevar la distinción de su mujer cuando le regalaba joyas de oro, plata y piedras preciosas que realzaban su rostro. El arma más poderosa que utilizan los calaveras para conquistar alguna joven sin experiencia, de humilde origen son precisamente las joyas. Entre los aderezos de las mujeres de Ayguals de Izco encontramos sortijas, brazaletes, collares de variadas piedras. Matilde, modista de Lavapiés, se queda impresionada por la diversidad y la belleza de los regalos de Enrique expuestos en su tocador. A pesar de que su intuición le dice que se está engañando, ella quiere creer que todo el espectáculo es una prueba de amor y de sus intenciones de casarse con ella, mientras Enrique tiene otros planes:

¿Qué hermosas sortijas!... iQué pendientes!... iY este collarcito con su cruz de brillantes? iOh! iQué mono es!... Pero nada... nada como este riquísimo aderezo de rubíes... iCómo me gustan a mí los rubíes!... Veamos lo que hay en esta cajita... iOtro collar con tres hileras de piedras! ... Y su correspondiente alfiler... y sus pendientes prolongados... iQué bien me sientan a mí las perlas! (Justicia divina t. I: 418)

Todos los vestidos de gala van acompañados de alguna pieza de joya cuya calidad, tamaño y belleza dependen del estado financiero del que lo lleva: Elisa la marquesita de Verde Rama luce un collar de brillantes que destaca su "cuello de cisne" (Bruja de Madrid 
t. I: 149). Rosa en la ópera luce sobre los guantes unas pulseras de tres hileras de topacios engastados en oro (Marquesa de Bellaflor t. I: 116). Las que no tienen dinero, marido ni protector llevan "perendengues falsos" que "el mismo efecto producen que si fueran de brillantes". A Juanilla sus "joyas" le han costado catorce reales, pero la bisutería es más difícil de mantener, hay que sacarle brillo con un trocito de guante viejo de cabritilla (Bruja de Madrid t. I: 218). Cuando tenga un novio rico, ya las cambiará por algo más lujoso. Cuando eso por fin ocurre, en el baile aparece en "un vestido de gro amarillo, un precioso prendido de frutas artificiales, entre hojas verdes guarnecidas de brillantes que parecían querer imitar el roció y brazaletes de gran valor" (Bruja de Madrid t. I: 298). A las chicas humildes pero virtuosas, a diferencia de Juanilla, no les queda otra cosa que soñar con tener alguna pieza de joya que lucen las jóvenes de las capas altas de la sociedad. Es el caso de Enriqueta, la hija del pintor Federico, que fantasea con un viaje a Roma, teatros, lujosos trajes, un aderezo de perlas y una diadema de brillantes (Bruja de Madrid t. I: 211).

Entre los aderezos que se ponen de moda en este siglo hay que mencionar los medallones. En las novelas analizadas el más conocido es el medallón de oro de María, que recibe del marquesito Bellaflor como regalo de despedida, antes de su desafío. Estas piezas de joyería solían incluir inscripciones amorosas o retratos en miniatura de los seres queridos y el de María no era diferente. En el interior guardaba el retrato del marquesito y nunca se separaba de su medallón. Eso lo descubrirá la marquesa de Turbias-Aguas cuando decide quitárselo y asesinarla. Ayguals vuelve al medallón en varias situaciones a lo largo de la trilogía, destacándolo siempre como la pieza predilecta de la marquesa. Solo una vez, en la escena de la ópera, esta pieza aparece en una cinta de moaré y no en una cadena de oro. En ausencia de su marido María en él busca consuelo, como una heroína romántica "abrió cautelosamente el medallón, fijó la vista en el retrato, cubrióle de besos, prorrumpió en aglomerados sollozos" (Marquesa de Bellaflor t. II: 91; Palacio de los crímenes t. l: 686). Enriqueta lleva otro medallón de oro que esconde el secreto de su nacimiento. El pintor y su esposa la encontraron cuando era bebe con este medallón y la criaron como su hija. En el desenlace se descubre el verdadero origen de la niña y que su futuro marido, el condesito de Azucena realmente es su hermano (Bruja de Madrid t. II: 473). En la riqueza de aderezos sobresale la duquesa de Riansares, María Cristina. A pesar de ser el blanco de sus continuas críticas de la opulencia de los aristócratas y clases gobernantes, destaca su buen gusto, educación y su talento y el interés por el arte. La presenta como una amable persona, buena conversadora, aunque a veces sarcástica. Pero sobre todo su estilo a la hora de vestirse y combinar joyas:

Sus graciosos tocados, tachonados de costosísimos brillantes, sus magníficos aderezos de enormes perlas o encendidos rubíes, sus brazaletes de diamantes, guardaban la debida armonía, con la plata y el oro que recamaba las más preciosas sederías de los cortinajes (Palacio de los crímenes t. I: 175). 
Por otro lado, la mayoría de las señoras de nuevo cuño con sus vestidos, joyas y complementos quieren mostrar su nuevo estatus social. Derrochan dinero en las prendas de última moda, pero les falta estilo para combinarlas. Plumas, lazos, volantes, chales de cachemira, guantes, "sortijas en los dedos de entrambas manos", pulsera, reloj de perlas y encima un ramillete de flores, es solo uno de los atuendos exagerados y de poco gusto de la marquesa de Turbias-Aguas (María t. I: 160). La imitación de los ricos a menudo resulta en una escena cómica, la señora Antonia "había elegido tal diversidad de colores, que no dejaba de tener su conjunto alguna semejanza con el guacamayo, salva la diferencia de volumen; pues era de elefanta el de la buena señora" (Bruja de Madridt. I: 209).

Antes de acabar, un par de palabras sobre los peinados. En las novelas de Ayguals de moda están los rizos y bucles. Rosa lo lleva partido "en dos lisas mitades que se ondeaban sobre la frente" (Marquesa de Bellaflor t. I: 116). La condesa de Charco también lleva rizos "que ondulaban sobre sus sienes" (Marquesa de Bellaflor t. Il: 414). Eloísa se ha decantado por la moda inglesa, pero es indecisa a la hora de añadir adornos a su peinado. Siendo una niña rica, mal criada y presumida, Ayguals decide presentarla con un atuendo falto de mesura. La vemos delante del espejo, en un momento de inseguridad, intentando en vano conseguir una presencia elegante, sin ningún tipo de excesos:

También me favorecen los rizos largos a la inglesa... [...] Es tocado que no está muy bien a las rubias. No sé si estaría mejor una rosa artificial de un encarnado muy vivo aquí a la izquierda donde empiezan a desprenderse los bucles; pero como he puesto ya un lacito azul. (Los pobres de Madrid: 291)

Como testimonio de una época y sus modas encontramos referencias al peinado que introdujo la bailarina Sofía Fuoco, conocido como el peinado "a la Fuoco" ${ }^{4}$, que las damas de una tertulia rechazan como algo ya pasado "a favor de lazos y flores en los bandós" (Justicia divina t. II: 330). La prueba de que este peinado marcó una época y un estilo, la encontramos en varios textos costumbristas y en algunas novelas. Galdós en su novela Narváez comenta que era "no menos famoso que sus pies" (2003: 79). Los peinados de noche son más altos y se caracterizan por rizos adornados con flores, cintas, tiaras y bucles sueltos. El furor de los rizos era tal que se añadían postizos al moño. Esta práctica es duramente criticada por Ayguals como una manifestación de la hipocresía de la sociedad de su tiempo y del miedo a "el qué dirán", que convierte las personas decentes en las víctimas y el blanco de las habladurías. Pero no se muestra igual de empático con los personajes negativos, en esos casos esta práctica le sirve como una herramienta más para ponerles a ridículo. La pobre marquesa de Turbias Aguas no solo

${ }^{4} \mathrm{He}$ aquí como lo describe Cambronero (1913: 7) “Este peinado, puesto muy en relación con los tiempos de Luis XIV, aparta de la cara el pelo que tanto la adorna, debiendo poseer una belleza superior la niña que tome por modelo la cabeza de la célebre bailarina. Únicamente el calor de estación podrá generalizar una moda que no a todos los rostros favorece."

BEOIBERÍSTICA Vol. I / Número 1 (2017) | 81-92 
lleva "negros y lustrosos bucles" postizos sino también la dentadura (María t. I: 159). Esto recuerda al mundo de máscaras de Larra y a las señoras de edad con el cabello blanco teñido que guardaban su dentadura postiza en una cajita al lado de la cama.

Al igual que los costumbristas de la época, en las novelas de Ayguals los aspectos relacionados con modas han sido reflejados minuciosamente. El afán de objetividad en la representación del mundo circundante de Ayguals de Izco queda patente, como ya hemos visto, en la manera de vestir de sus personajes. De hecho, la imparcialidad aparece como uno de los imperativos de su concepción del novelar. La novela debe ser la expresión directa y fiel de la realidad, "el enlace y desarrollo de la fábula dramática" tienen que seguir "los principios de la escuela más sublime", "la escuela de la naturaleza, la escuela de la verdad" (María t. II: 384). Por otro lado, uno de sus cometidos es enseñar y moralizar el pueblo, dar lecciones "ataviándolas con las poéticas galas de fábula" y sobre todo dar ejemplo. Es consecuente y sigue este modelo en todas sus novelas, introduce varios personajes negativos y recrimina su comportamiento reprobable, destacando a los positivos como modelos de virtud $y$ honestidad. Porque solo conociendo los males personales y sociales uno los puede combatir. La misma línea sigue en la representación de su aspecto físico y su atuendo, a los malos de la sociedad alta los pinta como personas que se caracterizan por falta de buen gusto y medida a la hora de vestir y les contrapone el ejemplo de los ricos buenos. Como hemos visto, en las novelas de Ayguals de Izco es posible identificar y seguir una buena parte de los cambios que han sufrido no solo la moda femenina sino también la masculina a lo largo del siglo XIX, ya que abarcan el período desde el año 1801 hasta el 1859. Estos cambios son resultado de los cambios de la sociedad española y nacen en gran medida del deseo de las clases altas de diferenciar sus atuendos de las clases inferiores.

\section{BIBLIOGRAFÍA}

\section{Literatura primaria:}

Ayguals de Izco, Wenceslao. María la hija de un jornalero. Historia-novela original, 2 vols. Madrid: Imprenta de Wenceslao Ayguals de Izco, 1847. Impreso.

- La marquesa de Bellaflor o el niño de la Inclusa. Historia-novela original, 2 vols. Madrid: Imprenta de Wenceslao Ayguals de Izco, 1847-1848. Impreso.

-. Pobres y ricos o la bruja de Madrid. Novela de costumbres sociales, 2 vols. Madrid: Imprenta de Wenceslao Ayguals de Izco, 1850-1851. Impreso.

- El palacio de los crímenes o El pueblo y sus opresores, 2 vols. Madrid: Imprenta Ayguals de Izco Hermanos de Izco, 1855. Impreso.

- Los pobres de Madrid. Novela popular, Madrid: Imprenta de Ayguals de Izco Hermanos, 1857. Impreso. 
-. La Justicia divina o El hijo del deshonor: novela original española, 2 vols. Madrid: Imprenta de Wenceslao Ayguals de Izco Hermanos, 1859. Impreso.

Literatura secundaria:

Aparici, Pilar e Isabela Gimeno. Literatura menor en el siglo XIX: una antología de la novela de folletín (1840-1870). Barcelona: Anthropos, 2003. Impreso.

Benítez, Rubén. Ideología del folletín español: W. Ayguals de Izco (1801-1873). Madrid: José Porrúa Turanzas, 1979. Impreso.

Burguera Nadal, María Luisa. Wenceslao Ayguals de Izco. Análisis de Pobres y ricos o La bruja de Madrid. Vinaroz: Antinea, 1998. Impreso.

Cambronero, Carlos. "Crónicas del tiempo de Isabel Il". La España moderna, núm 296. Madrid: Casa editorial La España moderna, 1913: 5-33. Impreso.

Carmona González, Ángeles. La mujer en la novela por entregas del siglo XIX. Sevilla: Caja san Fernando, 1990. Impreso.

Gautier, Théophile. Viaje por España, Barcelona: Taifa, 1985. Impreso.

Labanyi, Jo. "Being there: The Documentary Impulse from Ayguals de Izco to Galdós". Studies in Honor of Vernon Chamberlin, Newark: Juan de la Cuesta, 2011: 95-109. Print.

Mesonero Romanos, Ramón. Escenas matritenses por curioso parlante, vol. 3-4. Escenas matritenses, t. III. Madrid: Imprenta de Yenes, 1842. Impreso.

Pérez Galdós, Benito. Narváez. Alicante: Biblioteca Virtual Universal, 2003. Web. 20 Dic. 2016.

Reyero, Carlos. "Gusto y libertad. El arte en la novela María o la hija de un jornalero, de Ayguals de Izco". Anales de Historia del arte, volumen extraordinario (2008): 474-488. Web. 20 Dic. 2016.

—. "Novela histórica y folletín”. Anales de Literatura Española, núm. 1 (1982): 270-282. Impreso.

Sebold, Russell P. En el principio del movimiento realista. Credo y novelística de Ayguals de Izco. Madrid: Ediciones Cátedra, 2007. Impreso. 